\title{
O estatuto da crítica
}

Luiz Costa Lima

\section{Resumo}

O texto faz parte de um debate sobre a posição da crítica literária quanto à questão do método. De fato, contudo, o autor, não se julga defensor de algum método em critica literária, o que vale dizer, o divisor básico hoje em dia na abordagem literária não concerne ao ataque ou à defesa do método. Nem por isso, entretanto, há algum denominador comum na abordagem teórico-crítica. Isso aqui se mostra pela contraposição à chamada crítica desconstrucionista, mais especificamente contra conceitos-chaves da abordagem de Jacques Derrida.

Palavras-chaves: Desconstrucionismo, Derrida, referencialidade, différance, metáfora, indeterminação, indecidibilidade 
Minha presença aqui decorre de meu nome haver sido sugerido para participar de um confronto entre defensores de duas posições: aqueles para os quais a crítica literária é uma atividade contra o método e os que defendem ela implicar um método. Embora me surpreenda ser incluído na alternativa, como defensor do método, o lugar em que me põem é bastante aceitável se entender que a linhagem contrária é sustentada sobretudo pela obra de Jacques Derrida. Portanto, ainda que um fator de polidez contribua para minha aceitação, não é exclusivamente por ele que decido colaborar.

É oportuno que comece por argumentar por que me oponho aos chamados estudos desconstrucionistas.

Ainda estando em andamento uma discussão mais longa que faço de minha discordância com o textualismo derridiano, restrinjo-me aqui ao mínimo necessário. Não creio que seja trivializar o pensamento do judeu argelino que revolucionou o sistema acadêmico norte-americano declarar que sua intuição básica esteve baseada no caráter em que via fundada a linguagem humana: sua nuclearidade metafórica. Ela implicava que, na linguagem, não há diferença entre o sentido próprio ou literal e sua significação figurada. A afirmação da metáfora resultaria de uma "mitologia branca", como desenvolverá no ensaio de mesmo título (cf. Derrida, J.: 1971), i.e., que apaga a diferenciação das cores, que daria a peculiaridade desta mitologia quanto àquela, daquela contra aquela outra, provocando, portanto, uma usura da imagem, cujo lugar, sempre mutável e sensível à posição que ela ocupa numa cadeia de signos, é substituído por um sentido estável, tendencialmente fixo, metafísico. Metáfora e metafísica derivariam do mesmo propósito de fazer com que a estabilidade substituísse a incômoda dinamicidade incessante do mundo e da produção textual humana; a conversão seria possível porque todo signo verbal, enquanto nomeador de algo, sempre equivale a uma moeda cuja efígie fosse progressivamente desgastada pelo uso. A distinção entre sentido próprio e figurado indicaria uma arbitrariedade multissecular, acolhida pelos tratados de retórica, admitida por aquele desgaste.

Todo o aparato pressuposto pela "mitologia branca", com a corrosão da efígie que transforma a palavra em uma moeda lisa conduz ao conceito mais famoso de Derrida: o de différance ainda que foneticamente idêntico a "différence", deste se distingue porque deriva de différer (diferir, adiar, prolongar, procrastinar). Ou seja, submetida a um fluxo metafórico contínuo, a palavra, em vez de designar, como quem apontasse com o dedo, move-se e serpenteia, nunca se restringe a ser isso ou aquilo, pois sempre está sendo. Que, portanto, provoca esse efeito de diferir, contra o qual se erguem metafísicas e retóricas? Que, afinal, tanto se difere? Difere-se, retarda-se a conclusão de qualquer argumento - pelo menos, desde que ele não se confunda com uma resposta 
pragmática banal. (Que pode haver de mais corriqueiro do que um cumprimento automático? Porém, se a um trivial 'bom dia", respondo: "você acha?", o interlocutor ou entenderá que a réplica é brincalhona ou ficará intrigado. $\mathrm{O}$ inesperado da resposta dissolve o clichê e o fluxo de logos restabelece a dúvida e a inquietação). Dito de modo mais preciso: vista em sua potencialidade, a nomeação, enquanto manifestação humana, é sempre o produto de um deslocamento - não se esqueça que 'metáfora' significa em grego 'viagem, travessia'. Por conseguinte, a différance ressalta que um enunciado traz consigo a possibilidade de nunca alcançar a plena decifração. Independente da vontade de quem fala, dizer provoca o diferir do que se pretendia concluir. A decisão conclusiva é sempre passível de ser retorcida, assumir outra volta, ser entendida ao revés, a ofensa virar louvor, o louvor, advertência, etc, etc. E tudo porque o que se diz guarda um resto, imprevisto mas nele assente. Por isso supor a decifração plena da verdade corresponde à crença na verdade absoluta, produto por excelência da concepção metafísica da linguagem. A metafísica equivale a um corpo pesado que busca tornar estável a frágil leveza que somos. Daí, recorrendo ao título de seu ensaio sobre a semiologia hegeliana, "Le puits et la pyramide" (1971b), a metafísica ser comparada à pirâmide, o volume liso e pesado que guardaria o corpo mumificado do faraó. Por oposição à pirâmide, o poço corresponderia à fluidez abissal de logos.

Lado a lado da oposição entre poço e pirâmide, põe-se a idêntica e drástica separação entre logos e escrita. A escrita, como já dissera em "La pharmacie de Platon", é um "morto vivo, um morto em sursis, uma vida diferida, uma aparência de sopro" (Derrida, J.: 1968, 179); "a magia da escrita e da pintura é, portanto, a de um fardo que dissimula o morto sob a aparência do vivo" (idem, 177); enquanto identificada com a figura do estático, do piramidal, a escrita se põe ao lado da verdade "como possibilidade da repetição e da submissão (...) à lei (...)" (ibidem, 152). Logos, ao contrário, é a palavra dançarina, correspondente à formulação semi-heideggeriana: "Die Sprache spricht, nicht nur der Dichter".

Que significa que "a fala fala e não só o poeta"? senão que, por ela, a différance atinge seu máximo potencial. E assim sucederia simplesmente, porque, na ficção literária - Derrida diria apenas "na literatura" -, à sua não pragmaticidade se acrescenta a não referencialidade. (Tenho de resistir à vontade de interromper o resumo da posição derridiana porque cada vez mais me é difícil ser justo com um argumento de que discordo por completo. Introduzir aqui, contudo, a contraposição ainda não seria correto. Quando nada, preciso explicar por que Derrida e os desconstrucionistas excluem a referencialidade da ficção literária). Para me aproximar do entendimento que ofereceria o pensador francês preciso recordar a diversidade do que sucede com o conceito. Esse, para ter assegurada a univocidade que pretende alcançar, precisa 
manter-se como metáfora desgastada e mesmo desbastar o que ainda dela reste, ao passo que a expulsão da referencialidade no poético decorreria, ao contrário, de ele afastar-se do sentido único. O sentido único supõe o uso do sentido próprio do signo. Contra ele, ou melhor comprovando a arbitrariedade de distingui-lo do sentido figurado, a poesia potencializa a profundidade do poço, os deslocamentos do corpo coleante da palavra.

Explicitadas as razões que levam Derrida e seus seguidores, com ênfase particular para Paul de Man, a relacionar o ficcional literário com a desreferencialidade, abro uma primeira brecha na linha expositiva a que acima me dediquei. Parto de uma afirmação a ser depois retomada. Se Derrida tem o inegável mérito de ser um leitor extremamente minucioso, em troca tem uma vocação generalizante no mínimo incômoda para o leitor cuidadoso. É o que tipicamente sucede no exame da referencialidade. Reconhece-se que o questionamento derridiano ressalta o fundo falso que sustentava a referencialidade: ela era considerada o correspondente extratextual do sentido próprio de um termo. Assim, árvore' teria como correspondente a figura maciça de um tronco de altura mediana para alta, encimado por galhos e folhas.

É evidente que se entendermos referencialidade deste modo ela só é cabível quanto ao signo em função indicial - "sim, disse a vítima, é ele mesmo quem me atacou". Mas uma certa diferença se estabelece se entendermos por referencialidade não $o$ dado factual $a$ que o signo aponta senão que o horizonte de correspondência que o signo traz consigo. Enquanto horizonte de correspondência, o referencial por certo pertence à ordem do mundo e não se esgota no campo lexicográfico. Os dicionários não seriam factíveis se pretendessem dizer do potencial de correspondência dos signos. Enquanto tal, o horizonte que traz a palavra em seu uso não cria a equivalência de duas ordens, a do mundo e a do léxico, senão que impede que as duas ordens permaneçam desconectadas. Por isso sua conexão não é pontual mas caracterizada como horizonte, pano de fundo que cria a ambientação para a cena.

Feita a retificação, é absurdo dizer-se que a poesia ignora a referencialidade. Por certo, desconhece, em absoluto, a equivalência pontual mas, se ela não se relacionar com um horizonte de sentido, significará aquilo que o intérprete, de algum modo legitimado - seja por pertencer a um país "metropolitano" ou a uma instituição de prestígio, seja por representar a corrente de antemão acatada - "demonstrar" aquilo que está a dizer. Desbastado seu entendimento grosseiro, pode-se acrescentar: a referencialidade acompanha todo ato da fala. Acompanha-se pela razão absolutamente oposta àquela em que se fundamentou sua concepção corriqueira, contra a qual se levantará a filosofia da linguagem contemporânea: a que se apresenta de modo sucinto na passagem dos Tópicos: "Uma definição é uma frase que indica a essência de alguma coisa" (Aristóteles, Tóp., I, 101 a 39). (Em relação a cuja 
concepção Barbara Cassin bem escreve: “E porque certas palavras têm um sentido sem que lhes corresponda essência alguma, devese recusar a proposição geral conforme a qual as palavras têm um sentido porque as coisas têm uma essência" (Cassin, B.: 1989, 38).

Desde a declaração mais corriqueira, ante a qual é impossível ignorá-la ou confundi-la, até o poema mais intenso em sua extrema síntese. Considere-se neste caso o "Mattina" de Ungaretti, exemplo a que em tantas ocasiões tenho recorrido. Ele consta de apenas dois versos:

\section{M'illumino \\ D'immenso}

O leitor dotado de um mínimo de sensibilidade compreenderá que o sujeito da frase não corresponde ou ao $\mathrm{eu}$ do poeta ou a outro qualquer eu. Sua referencialidade? A agência - humana objeto da invasão de imensidade que o transborda. Seu horizonte é o de uma claridade ímpar, que, no entanto, não se poderia dizer sem limites porque se percebe que é terrena, apenas humana, nada suprassensível ou concorrente de uma experiência mística. O referencial poético não se confunde com o de uma proposição qualquer. Mas, poético ou não poético, todo enunciado tem um referente.

Tomo ainda um outro exemplo. Digamos que me defronte com a frase: "Luz! Mais luz!". Embora banal, ela se torna incompreensível se não se conhecer o contexto a que alude. E como ignorarei que tem um referencial específico, que mais bem manifestaria a vontade de permanecer em atividade de vida do que algum conteúdo dramático, se recordo que eram as palavras pronunciadas pelo Goethe moribundo? Não se diz que a frase, por ter sido pronunciada por Goethe, se torna poesia (!), senão que, como no "Mattina", não é entendida se não se considerar o contexto pelo qual é precisado seu horizonte de sentido. Sem que esse seja pontual, muito menos aquele ou algum outro, o horizonte referencial supõe a compreensão da ambiência em que se dá - seja a página de um livro, seja um leito de morte.

Suspendi a exposição que procurava que fosse a mais imparcial possível pela afirmação terminante de uma restrição quanto a um ponto decisivo do pensamento de Derrida. Desde aí, contudo, desfiar as progressivas divergências seria algo demasiado esperável. É preferível confrontar-me com o pensamento sob exame, vendo-o sob o ângulo especial a que o submete Peter Sloterdijk, em um ensaio tão pequeno quanto notável.

O propósito do pensador alemão, em Derrida, um egípcio, não era nem atacar, nem defender o autor que há pouco havia morrido, senão que pensar sobre seu legado. Procuro resumi-lo para, a partir daí, verificar que desenvolvimento lhe darei. 
Fundando-se em obra póstuma do historiador da arte Franz Borkenau ${ }^{1}$, Sloterdijk partia de as culturas derivarem de uma alternativa:

Enquanto um dos tipos de cultura rejeita a morte e reage com uma doutrina da imortalidade, o outro se resigna e desenvolve, fundamentalmente, uma cultura comprometida com este mundo. Borkenau qualificava essas opções bipolares como 'antinomia da morte' (Sloterdijk, P.: 1986, 40).

Comprometidas com a aceitação da morte, as culturas grega e moderna [não é acidental que um dos temas capitais que essa acolhe esteja no antagonismo entre a tese da secularização - "Todos os conceitos pregnantes da moderna teoria do Estado são conceitos teológicos secularizados" (Schmitt, C.: 1922, 43) - e sua recusa terminante por Hans Blumenberg (cf. Blumenberg, H.: 1966)] - divergem na raiz das que asseguram a imortalidade (Egito, Jerusalém, Roma). Sloterdijk recorda a tese de seu compatriota para logo acrescentar que Derrida não optava por uma ou outra linha, senão que mantinha uma linha de compromisso entre elas. A escrita (écriture), morta-viva, é o seu lado piramidal, ao passo que a fluidez do signo seria indicativa da vida de logos, sempre entrecortada pelo incessante deslocamento do sentido. Daí caber a Derrida tanto a afirmação que valeria para o desconstrucionismo em geral - "Poder-se-ia descrever o procedimento desconstrutor como um manual de instruções, a fim de permitir a transmissão das igrejas e castelos do ancien régime metafísico e imortalista para as mãos dos mortais civis" (Sloterdijk, P.: idem, 44) - como a de direção contrária: "(A desconstrução) significaria uma tentativa de associar igualmente o pertencimento da cidade moderna dos mortais a uma opção em favor do imortalismo egípcio" (ibidem, 47). Serem as direções contrárias, não significa que Sloterdijk procurasse com elas desmerecer o amigo morto, senão apenas assinalar que esse se punha na confluência de linhagens contrapostas.

\section{$\mathrm{X} X \mathrm{X}$}

Se expus as teses contrárias com boa vontade e mesmo

1 Sloterdijk cita sua edição em alemão, sem indicar sua data de publicação. Como Borkenau, austríaco de nascimento, passara a viver na Alemanha, nos anos 20 , e, com a ascensão do nazismo, se exilara na Inglaterra, sua obra póstuma, como acentua seu editor Richard Lowenthal, é formada tanto por textos escritos originalmente em alemão como em inglês. $\mathrm{Na}$ falta de cotejo com a edição mencionada por Sloterdijk, tomo a em língua inglesa como a original. simpatia, por que não as endosso? Lembro a sábia advertência do filósofo: a qualidade de teu trabalho pode depender da escolha de teu adversário. Mas o que importa é a razão da discordância com o que expus. Resumo-a aos mínimos pontos capitais.

(a) Seja a primeira a que afirma que um conjunto de enunciados formadores de uma linha argumentativa se apresenta como uma cadeia metafórica desgastada. Essa cadeia constituiria, portanto, uma "sedimentação metafórica dos conceitos" (Derrida, J.: 1971, 255), sedimentação responsável pela "camada de 'primeiros filosofemas' "(idem, 261), de que resulta que a suficiência dos conceitos e dos primeiros filosofemas é sempre uma ilusão de unici- 
dade; poderíamos dizer é um engano "piramidal", pois dá a entender que, por fim, se conseguiu fazer cessar as contínuas reviravoltas e deslocamentos de sentido. Sem entrar em uma discussão filológica para a qual não sou competente, e mesmo que admita que "a teoria da metáfora (...) parece pertencer à grande cadeia imóvel da ontologia aristotélica" (ibidem, 281), que, por conseguinte, o "sol" nele se multiplica em um sistema estelar (cf. ib., 291), daí não se conclui que, ao ter sua efígie desgastada, a metáfora lisa continue a funcionar como metáfora. O que equivale a dizer: a crítica da metafísica e da verdade como substância e, assim, indestrutível, firme e inamovível assume em Derrida uma tamanha totalidade que reproduz, pelo avesso, a própria vocação totalista da metafísica. Nele, se tem a defesa do singular que paradoxalmente eleva a singularidade à condição de totalidade. Daí o engano que, como Sloterdijk observa, favoreceu o próprio Derrida: a muitos sua reflexão deu a entender que a desconstrução era "a derradeira oportunidade para uma teoria integrar por meio da desagregação" (idem, 17) quando, em verdade, era a figura final de um processo lógico, o "da virada linguística ou semiológica" a que, no século $X X$, foram submetidas "as filosofias da linguagem e da escrita" (ibidem, idem). Porém o mais grave não está em considerar novo o que era o ato a mais de uma peça já encenada senão na pretensão de dizer da linguagem em termos absolutos, sem considerar que sua função se modifica de acordo com a disposição discursiva em que ela está sendo usada. Ao ignorar a diversidade dos modos discursivos, Derrida converte o propósito de destruir a metafísica em equivalente ao que julga idêntico à desmistificação de toda forma de pensamento, ou seja, idêntico a negar a ambição de algum enunciado ser pura conceitualidade;

(b)Papel da différance: dentro da ambição totalizante, que esperava "integrar por meio da desintegração" (Sloterdijk), para Derrida, onde haja linguagem, ao menos onde ela não se confunda com uma nomeação banalizada, o diferimento que processa significa o estabelecimento de uma indecidibilidade. Contra o decisionismo político de Carl Schmitt - cujo pensamento é aqui lembrado porque, nos mesmos anos 70, suas obras recomeçavam a circular fora da Alemanha - a indecidibilidade derridiana se mostraria como seu avesso irônico, cuja aparência radical era, na verdade, algo ocioso. 
Pode ser proveitoso levar adiante o cotejo. Por que a indecidibilidade, do ponto de vista de Carl Schmitt, seria ociosa? Porque decisionismo era formulado como um meio para a luta política, enquanto a indecidibilidade antes se assemelharia à "conversa infinita" com que Schmitt caracterizava a atitude liberal, que, tornando o sujeito individual o verdadeiro centro do regime, convertia o liberalismo em impotente para enfrentar os regimes de força. Por que avesso irônico do decisionismo? Por dois motivos. De imediato, porque, dentro de uma ortodoxia derridiana, a postura de Schmitt ignorava a propriedade mínima da linguagem: a decisão criaria um dique que o fluxo da linguagem terminaria por rebentar. Em segundo lugar, porque o auge de prestígio da différance e, em consequência, do indecidível, nas universidades norte-americanas, levava os desconstrucionistas a discriminar autoritariamente os que não concordassem com eles. Ou seja, teoricamente desinteressados pela luta política na prática, "decidiam" pela exclusão de seus adversários. ${ }^{2}$

O contraste acentuado não teria sentido - afinal Schmitt e Derrida tratavam de objetos bastante diversificados - caso não fossem seus pontos de contato não fossem pontos de atrito: se, por um lado, o decisionismo pareceria algo rude e, portanto, diante do qual os defensores da indecidibilidade poderiam permanecer ociosos ou ironicamente separados, por outro, quando esses exerciam posições de mando mostravam saber decidir do modo mais peremptório: por exclusão dos divergentes.

Considere-se o caso ilustrativo do que de fato sucede com a différance: seu desinteresse por assuntos ou disputas tão-só acadêmicas era apenas uma aparência, e decorria da entonação totalista contida no pensamento derridiano. Por efeito de seu totalismo, em vez de considerar a différance como provocadora de um inevitável indecidível, considero que, no próprio texto poético, a indecidibilidade - i.e., a terminante impossibilidade de dizer-se qual o sentido de um poema - é tão-só uma entre duas possibilidades, sendo a outra, a indeterminabilidade - i.e., o sentido é passível de ser declarado, embora nunca se possa dizer que ele seja o único e estavelmente fixado. ${ }^{3}$

Como já considerei a questão da referência não estranharia que a muitos seu retorno pareça extravagante. Sucede porém que a posição assumida por Derrida e os desconstrucionistas em peso não foi inaugurada por eles. Como já se disse acima, confundir a referência com um duplo natural do signo a tal ponto generalizou-se que ainda agora questionar sua negação chega a parecer inconcebível. Como primeiro sinal do que sistematizarei a seguir como próprio da postura que tenho assumido, devo, portanto, insistir sobre o questionamento da repulsa da referencialidade.

Vale partir de uma observação que ouvi do poeta João Cabral. Visitava-o em seu apartamento do Rio de Janeiro, onde estava de férias de alguma embaixada na América Hispânica. 
Meio irritado, meio irônico, me contava que recebera à tarde a visita de uma professora de literatura. Conforme o poeta, ela queria saber se a referência frequente à cana de açúcar, em seus poemas sobre o Nordeste, não trazia uma carga fálica. Ainda exasperado, João acrescentava: por que esta sua colega não considerou que eu venho da zona da mata de Pernambuco onde, desde criança, convivi com a paisagem dos canaviais? Tiro do episódio uma consequência banal: a palavra, mesmo a poética, por certo que desconhece uma referência unívoca, mas tomá-la como se solta no mundo, juntando-se aleatoriamente a qualquer outra e então passível de sustentar uma simbologia qualquer, seria viável apenas para um surrealismo facilitado e/ou promotor de uma poesia que confunde o inefável a que aspira com a arbitrariedade que pratica - os exemplos são tão frequentes quanto a permanência do desdém pela teorização. Em suma, a referência, desde a imediata - alguém entra na sala e pergunta: "quem aqui é Pedro?" - até a mais alusiva é uma sombra que sempre acompanha a palavra. Seu desdém é tão estúpido como o realismo banal a que usualmente está associada. Se próprio da imagem é sua potencial plurivocidade, pela qual ela se põe na antítese do conceito, negar a referencialidade termina por implicar que, diante do mundo, o comércio com a linguagem, supõe de duas uma: ou a pura objetividade que configura o conceito ou a intensa subjetividade estimulada pela imagem. É ainda de se acrescentar: o conceito, entendido como operador científico, tem um referencial a posteriori. (Algo que se pareça com um limão não é necessariamente incluído entre os cítricos). A referencialidade do conceito, na acepção filosófica, tampouco se estabelece a priori. Ou seja, não é por sua relação com a referencialidade que o operador científico se diferencia do conceito filosófico, senão pela maneira como um e outro se "aproximam" do que tratam - o operador manipula seu objeto, o conceito o tematiza. Quanto à imagem, ser ela plurívoca não quer dizer que signifique o que pretenda nela ver quer o engenho, quer o primarismo do leitor. Mais relevante que essas considerações sobre o papel da referencialidade na ciência, na filosofia e na ficção literária é levar em conta que o fenômeno da linguagem assume feições distintas de acordo com a modalidade discursiva em que se mostra. (Modalidade discursiva, i.e., análise das distintas formas discursivas é algo que não se encontra em Derrida. Mas tampouco posso aqui mais do que dizer que a abordagem linguística do discurso muito menos é satisfatória).

$$
\mathrm{x} \times \mathrm{x}
$$

A partir dos pontos destacados, posso agora me perguntar: sou então defensor de um método, em crítica literária? Sem qualquer sofisticação, entendo por método o conjunto de procedimentos reiterados que visam ao alcance de certo resultado previsto. Os exames médicos rotineiros a que nos acostumamos obviamente se processam de acordo com um método. A importância que as 
ciências assumem em nosso cotidiano é contudo responsável pelo uso abusivo do termo. E passa-se a chamar de 'método' não só o que é habitual na conduta de alguém como se exige a declaração de método onde ele não se dá. Assim, por exemplo, os formulários a serem enviados aos institutos de apoio à pesquisa, costumam indagar aos que pretendem bolsas ou outra forma de ajuda, nas ciências humanas, que método será usado em seu trabalho. $\mathrm{O}$ solicitador então terá de dar voltas à capacidade de forjar sentido para frases inócuas, enquanto seu colega em ciências da natureza simplesmente indicará o nome de um procedimento reconhecido. A competência administrativa de uma instituição por certo não se mede pela capacidade de seus funcionários em saber o que distingue a prática entre as ciências "duras" e as humanidades. Nem por isso é explicável que continuem a ser impressos formulários com semelhantes questões. Seja o caso da análise de um texto poético-ficcional. Empregar a seu propósito um método significaria supor que há etapas fixas, pelas quais se pretenderia, ante a positividade de resultados já alcançados, alcançar um certo resultado. Diante de certo procedimento analítico, o texto deveria reagir como uma substância química ao contato com certo reagente. Ora, alguém que tenha de fato aprendido com a própria experiência saberá que cada autor exige que se desenvolva uma abordagem específica. Na formulação tão sumária como precisa de Ernst Jünger: "Os autores diferem entre si como diferem os peixes, os pássaros, os insetos". Ao contrário de uma aplicação metodológica rotineira, aqui não há qualquer previsão de um certo resultado ou mesmo de chegar-se a resultado algum. Podese até lamentá-lo, mas a rotina não é esperável na tarefa analítica no campo literário. Negar a expectativa de rotina não equivale a dizer que qualquer procedimento torne-se então válido. Se, pela dificuldade que encontro em certo texto ou autor, adoto os princípios da direção que atrás se indicou como contrária ao método, demonstro apenas que meus princípios teóricos não devem ser levados a sério.

Em suma, portanto, mostrar-me contrário aos princípios que orientam a prática desconstrucionista não supõe que eu proponha algum método. Na posição que defendo e orienta minha prática analítica, o que mais se aproxima de uma afirmação metodológica seria a de que cada área discursiva (a ficcional, a das ciências da natureza, a das ciências humanas, a da filosofia, a da religião, a das interrelações pragmático-cotidianas) exige modos de indagação diferenciados. Quando algum deles admite ou mesmo passa a exigir um certo método será pela combinação de duas condições: (a) que a operação analítica já tenha apresentado resultados tão constantes que possa ser usada automaticamente e (b) que o objeto mostre uma alta previsibilidade de comportamento. Se essa combinação não fosse frequente, as ciências não teriam ganho o prestígio que hoje têm. Mas, se as próprias ciências fossem apenas 
reiteradoras de métodos já afirmados, elas não avançariam. E, se avançarem graças apenas à argúcia do pesquisador, enquanto o objeto mostrar condutas imprevistas? Neste caso, já não se estará tratando com uma área científica. Para comprová-lo, sugiro que desconsiderando a patente orientação a favor da imagem, concentrada na qualificação de 'crueza', - leia-se a seguinte passagem: "Quem pensa em conceitos e não em imagens, procede diante da linguagem com a mesma crueza de quem vê apenas as categorias sociais e não os homens (Jünger, E.: 1949, II, 59).

Mesmo desconsiderando o manifesto parti pris de Jünger, é evidente que, nas ciências humanas, só as categorias sociais podem oferecer um grau aproximado da estabilidade dos fenômenos naturais; por isso só elas são passíveis de alcançar um certo grau de cientificidade.

Isso posto, posso acrescentar uma razão extra para me orientar pelo caminho que assumo: se, em vez de uma visão totalistametafísica, acentua-se a necessária diversidade de campos discursivos, assume-se, em consequência, uma indispensável visão diversificada do signo. No signo, as direções passíveis de serem tomadas dependem da relevância de uma entre duas direções: a imagética e o nocional. ${ }^{4}$ É bastante sabido que, nas ciências ditas exatas, a dimensão imagética necessariamente estiola. Que interessa ao biólogo que o termo 'célula' tenha como lastro metafórico original 'pequena cela'? Em troca, se o analista do texto ficcional literário não considera essas diferenças, é arrastado a converter seu próprio texto em competidor daquele que examina. Se o ficcional literário, sobretudo em sua espécie poemática, é comparável a um poço interminável e indecidível, o texto analítico deveria então ter as mesmas qualidades. Que interessa compreendê-lo, se, enquanto poético, estará sempre aberto a outra compreensão? Para que então o analiso? Para saber-me responsável por uma de suas variantes interpretativas? Por isso a crítica desconstrucionista, ao se recusar a reconhecer uma diferença capital entre ela e o texto sobre o qual se dobra, ou assume um panficcionalismo ou afirma de si que é um gênero tão poético como seu objeto. Deste modo, sob o pretexto, correto, de que a crítica não é julgamento senão que indagação dos limites da razão, o desconstrucionista torna-se um grande juiz: sua sentença consiste em deslocar o entendimento prévio e assente e, ao mesmo tempo, em desconsiderar quem não parta de seus pressupostos.

Contra tal curso, terei de dizer que a crítica por certo não é julgamento, mas juízo sobre os limites da razão - o imagético e as formas de conceitualidade (cf. nota 3) traçam limites para a

4 Prefiro falar em nocional para não voltar a distinguir entre o conceito, em sua acepção filosófica e em sua dimensão operacional, i.e., científica. razão. Se a crítica não é poética, nem por isso há de ser menos poiesis. Quando não alcança esse estágio, ela é algo que apenas serve para a premiação em concursos ou para discriminar entre autores que separa entre bons ou maus. Poiética, a crítica do ficcional literário não possui propriamente conceitos. Ora, se dela já 
afastamos a dominância imagética, onde, afinal, se sustenta? Em sua acepção científica, i.e., enquanto operador, o conceito é um enunciado tanto mais poderoso quanto mais unívoco. Sua univocidade é sua vantagem e, ao mesmo tempo, seu limite. O conceito da atração universal dos corpos é algo que, desde sua formulação, a humanidade não pode ignorar. Mas não se queira que ele diga mais do que diz. O conceito é literalmente Begriff, i.e., algo que agarra e prende. O latim forneceu ao alemão a possibilidade de um par, Konzept. Mas, no léxico corrente, Konzept significa 'esboço, projeto, programa'. Para que o termo diga de sua função na filosofia teríamos de ressaltar sua etimologia: konzipieren, derivado de concipere. A crítica é poiética à medida que supõe a abertura para uma concepção que ela então elabora. Longe de tornar as imagens ociosas, o poiético da crítica não compete com as voltas e giros, torsões e deslocamentos do ficcional literário, mormente de sua espécie poemática. Muito menos pretende alcançar a precisão e limite dos Begriffen. Ela visualiza o indeterminável, minoritariamente o indecidível. A crítica ativa o pensar; só ao tentar conciliar o inconciliável, passa a competir com o texto poemático: a fluidez do poço com o volume fixo da pirâmide. Contra essa possibilidade, a ativação da crítica pelos três tratados kantianos já nos tinha alertado. Não é acidental que, como corrente de agora, o desconstrucionismo ponha a crítica no ostracismo.

$\mathrm{X} \times \mathrm{X}$

Reservo uma última observação para o modo como me distancio do desconstrucionismo. Sloterdijk já disse que ele representou a esperança de que se conseguisse construir algo novo por meio da destruição. Neste sentido, Derrida foi um continuador de Nietzsche e Heidegger. Ora, ainda que se admita que essa promessa não se cumpriu não se pode negar que os instrumentos que aguçou trouxeram um sopro novo e deram maior maleabilidade ao ato de pensar. À minha posição, ao contrário, parece caber imagem de sentido bem diverso: como que ela volta a percorrer o campo do conhecimento, de que, depois de arado por vários sistemas de pensamento, ainda apresentasse, aqui e ali, alguns brotos que tivessem escapado ou colhidos de maneira imperfeita. Seria antes com esses restos que tenho trabalhado. É tipicamente o que sucede com o que tenho feito com a mímesis. Nos vários livros em que a considerei, procurei mostrar que não cogitava nem de recuperar seu sentido aristotélico, nem de nos aproximar do sentido que receberá na acepção hegeliana, sem que tampouco se pudesse pensar em alguma afinidade fosse com a tradição clássica da imitatio ou com a reflexologia em que o marxismo recaiu. Não vou aqui repetir senão que a retomada da mímesis inverte seu perfil: se ela guarda da velha acepção o princípio de correspondência entre textualidade verbal ou visual e configuração de um certo mundo, nunca tal correspondência dá a entender que o produto da mímesis seja uma segunda natureza, i.e., 
algo que se explique antes da configuração formal. Não poderia sê-lo porque entendo que a mímesis artística supõe a dominância do vetor diferença sobre um lastro - sempre mais distante quanto mais se caminha ao longo do processo de autonomização da arte - de semelhança.

Não vou nem desrotinizar a explicação acima, nem a prolongar até aos princípios de controle do imaginário e de ficção literária. Para os três casos, mantém-se correta a imagem de alguém que cuida dos restolhos que sobraram de campos amplamente cultivados. Duas interpretações seriam então possíveis: ou isso sucede por falta de inventividade de quem o tenha feito ou porque as colheitas anteriores eram feitos com instrumentos rudimentares.

Por mais diferentes que sejam as duas possibilidades nomeadas, elas têm algo em comum: a primeira indicaria o reconhecimento de que o que fiz não faria falta; a segunda daria a entender um gesto de presunção insuportável: o que antes de mim a propósito foi feito, tinha ferramentas toscas. A presunção seria tamanha que provocaria o mesmo resultado: o que a motivou pode ser esquecido, porque não faz falta. Como então evitar o pensamento de haver gasto a vida com inutilidades? Sem que apresente uma resposta definitiva, lembro o que Ernst Jünger afirmava em seu ultimo diário: "Ao saber pertence a dúvida" (Jünger, E.: 1949, III, 273).

\begin{abstract}
The text belongs to a debate in literary criticism on the question of method. As a matter of fact, the author does not consider himself as a defensor of a definite method. This means that the dividing line in current literary approach does not concern the question of method. What does not imply that there is a common denominator in today theoretical and critical approach to literature. That is the reason why the text below is characterized by its contraposition to the so-called desconstructionist critique, more specifically against Jacques Derrida's approach.
\end{abstract}

Keywords: Deconstructionism, Derrida, referentiality, différance, metaphor, indetermination, undecidibility

\title{
REFERÊNCIAS
}

ARISTÓTELES. Tópicos, trad. de Edson Bini, in Órganon, EDIPRO, São Paulo, 2005. 
BLUMENBERG, H.: Die Legitimität der Neuzeit (1966), ed. renovada em 1988, Suhrkamp Verlag, Frankfurt a. M., 1996.

BORKENAU, F.: End and beginning. On the generations of cultures and the origind of the west, R. Lowenthal (organ. e introdutor), Columbia University Press, New York, 1981.

CASSIN, B.: La décision du sens. Aristote. Le Livre Gamma, Vrin, Paris, 1989.

COSTA LIMA, L.: Mimesis, desafio ao pensamento, cap. VII: “O Paradoxo em Kafka", Editora Civilização Brasileira, Rio de Janeiro, 2000, pp. 365-395.

DERRIDA, J.: “La pharmacie de Platon" (1968), republ. in La Dissémination, Seuil, Paris, 1972, pp. 77-214.

DERRIDA, J.: "La mythologie blanche" (1971), republ. in Marges de la philosophie, Minuit, Paris, pp. 247-324.

DERRIDA, J.: "Le puit et la pyramide" (1971b), republ. in Marges, op. cit., p. 79-127.

JÜNGER, E.: Strahlungen II. Das Zweite Pariser Tagebuch (1949), DTV, Munique, 1965.

JÜNGER, E.: Strahungen III. Kirschhorster Blätter. Jahre der Okkupation, (1949), DTV, Munique, 1966.

SCHMITT, C.: Politische Theologie. Vier Kapitel zur Lehre von der Souveränität (1922), 8 ed., Duncker \& Humblot, Berlim, 2004.

SLOTERDIJK, P.: Derrida um égiptien. Le problème de la pyramide juive (2006), tradução de Evando Nascimento: Derrida, um egípcio. O problema da pirâmide judaica, Estação Liberdade, São Paulo, 2009. SPARIOSU, M.: "Mimesis and contemporary French theory", in Mimesis in contemporary theory, volume 1: The Literary and philosophical debate, Mihai Spariosu (organiz.), John Benjamins Publishing Company, Filadélfia - Amsterdam, pp. 65-108. 